\title{
Crosslinker Chemistry Determines the Uptake Potential of Perfluorinated Alkyl Substances by $\beta$-Cyclodextrin Polymers
}

Leilei Xiao ${ }^{1,2}$, Casey Ching ${ }^{3}$, Yuhan Ling ${ }^{3}$, Mohammadreza Nasiri ${ }^{4}$, Max J. Klemes ${ }^{1}$,

Theresa M. Reineke ${ }^{4 *}$, Damian E. Helbling ${ }^{3 *}$, and William R. Dichtel ${ }^{1 *}$

${ }^{1}$ Department of Chemistry, Northwestern University, Evanston, IL 60208 USA

${ }^{2}$ Department of Chemistry and Chemical Biology, Cornell University, Ithaca, NY 14853 USA

${ }^{3}$ School of Civil and Environmental Engineering, Cornell University, Ithaca, NY 14853 USA

${ }^{4}$ Department of Chemistry, University of Minnesota, Minneapolis, MN 55455 USA

\section{Supporting Information}

\section{Correspondence Address}

Professor William R. Dichtel

Department of Chemistry

Northwestern University

Evanston, IL 60208 (USA)

Email: wdichtel@northwestern.edu

Table of Contents

I. Materials and Instrumentation S-2

II. Synthetic Procedures S-4

III. Material Characterization S-9

IV. Batch Adsorption Studies S-14

$\begin{array}{lr}\text { V. References } & \text { S-17 }\end{array}$ 


\section{Materials and Instrumentation}

\section{A. Materials.}

Reagents for the synthesis of DFB-CDPs: Potassium carbonate (anhydrous, 99\%, free-flowing) was purchased from Sigma-Aldrich and dried at $120^{\circ} \mathrm{C}$ before use. Dimethyl sulfoxide (DMSO, anhydrous, $\geq 99.9 \%$ ) was purchased from Sigma-Aldrich. $4 \AA$ molecular sieves (Grade 514 ) were purchased from Fisher Chemical and activated at $170{ }^{\circ} \mathrm{C}$ under high vacuum overnight. $\beta$ cyclodextrin $(\beta-C D, \geq 97 \%$ ) was purchased from Sigma-Aldrich and stored in the dessicator. Decafluorobiphenyl (DFB, 99\%) was purchased from Sigma-Aldrich and used without further purification.

Reagents for the synthesis of EPI-CDP: Epichlorohydrin (99\%) was purchased from SigmaAldrich and used without further purification. Sodium hydroxide (Pellets/Certified ACS) was purchased from Fisher Chemical and used without further purification.

Reagents for the synthesis of IEM-CDP: All chemicals and solvents were purchased from Sigma-Aldrich (St. Louis, MO) and used without further purification, unless otherwise noted. 2Isocyanatoethyl methacrylate was purchased from $\mathrm{TCl}$ America and used without further purification. Food grade $\beta-C D$ was supplied by Wacker Chemie AG (Charleston, TN) and dried at $80^{\circ} \mathrm{C}$ under high vacuum before use. Dry dimethyl formamide (DMF) was obtained using an MBRAUN MB solvent purification system manufactured by M. Braun Inertgas-Systeme $\mathrm{GmbH}$ (Garching, Germany) using HPLC grade solvent.

Reagents for model reactions: Dimethyl sulfoxide- $d_{6}$ (DMSO- $d_{6}, 99.9$ atom\% D) was purchased from Cambridge Isotope Laboratories and used without further purification. $n$-BuOH (Certified ACS) and anhydrous $\alpha, \alpha, \alpha$-trifluorotoluene ( $\geq 99 \%$ ) were purchased from Sigma-Aldrich and used without further purification. Dimethyl sulfoxide (DMSO, anhydrous, $\geq 99.9 \%$ ) was purchased from Sigma-Aldrich.

Reagents for zeta potential measurements: $0.1 \mathrm{M}$ phosphate buffer solution ( $\mathrm{pH} 7.5$ at $\left.25^{\circ} \mathrm{C}\right)$ was purchased from Sigma-Aldrich and then diluted to $10 \mathrm{mM}$ with nanopure water.

Reagents for the quantification of phenolates by ICP-OES: Lithium ICP standard solution (1006 $\pm 2 \mu \mathrm{g} / \mathrm{mL}$ Lithium, 0.1\% (v/v) $\mathrm{HNO}_{3}$ ) was purchased from Inorganic Ventures and used without further purification. Nitric acid $(70 \%$, Purified by redistillation, $\geq 99.999 \%$ trace metals basis) and hydrogen peroxide ( $\geq 30 \%$, for ultratrace analysis) were purchase from Sigma-Aldrich and used without further purification. 
Reagents for PFOA study: Aqueous solutions of perfluorooctanoic acid (PFOA) were prepared using Milli-Q $\mathrm{H}_{2} \mathrm{O}$. Pollutant model compound PFOA (96\%) was purchased from Sigma-Aldrich and stored in the dessicator.

Reagents for PFAS panel study: Ten perfluorinated alkyl substances (PFAS) were acquired from Sigma-Aldrich (PFBA, PFHpA, PFOA, PFNA), TCl (PFHxA, PFBS), Alfa Aesar (PFDA), Santa Cruz Biotechnology (PFHxS, PFOS) and SynQuest Laboratories (GenX). Stock solutions of PFBA, PFOA, PFBS, PFHxS, PFOS, GenX were prepared in 100\% methanol. Stock solutions of PFHxA, PFHpA, PFNA, and PFDA were prepared in $96 \%$ methanol and $4 \%$ HPLC-grade water. All stock solutions were prepared at $1 \mathrm{~g} \mathrm{~L}^{-1}$. A mixture of all ten PFASs was prepared at a concentration of $1 \mathrm{mg} \mathrm{L}^{-1}$ in nanopure water.

\section{B. Instrumentation.}

Quantification of PFOA (50 $\mathrm{ng} \mathrm{L}^{-1}$ to $1000 \mathrm{ng} \mathrm{L}^{-1}$ ) from the adsorption studies in nanopure water was performed by means of Agilent 1200 Series high performance liquid chromatography coupled with a ESI-ion trap mass spectrometer Bruker Amazon X (USA). The mobile phase consisted of (A) Milli-Q water and (B) HPLC-grade methanol:water $=85: 15$ (Sigma-Aldrich, USA), each amended with $10 \mathrm{mM}$ ammonium acetate (Sigma-Aldrich, USA). Samples were injected at $20 \mu \mathrm{L}$ volumes and were loaded onto an ZORBAX Eclipse Plus (Agilent, Santa Clara, CA) C-18 column (Narrow Bore RR, $2.1 \mathrm{~mm} \times 50 \mathrm{~mm}$, particle size $3.5 \mu \mathrm{m}$ ) with a loading pump delivering $400 \mu \mathrm{L}$ $\mathrm{min}^{-1}$ of a mobile phase consisting of $85 \% \mathrm{~B}$. The column temperature was held constant at 40 ${ }^{\circ} \mathrm{C}$. The HPLC-MS was operated with electrospray ionization in negative polarity mode. MS/MS was operated and mass transition was $168.8(412.8 \rightarrow 368.9)$ or $412.8 \rightarrow 368.9$ for PFOA (Fragment ion $168.8(412.8 \rightarrow 368.9)$ was chosen when $\mathrm{m} / \mathrm{z}$ at $412.8 \rightarrow 368.9$ gave low $\mathrm{S} / \mathrm{N}$ ratio). Matrix-matched calibration standards $(n=7)$ were prepared with concentrations ranging between $50 \mathrm{ng} \mathrm{L}^{-1}$ to $1000 \mathrm{ng} \mathrm{L}^{-1}$ for external calibration. Analytes were quantified from calibration standards based on the PFOA responses by linear least-squares regression. Calibration curves were run at the beginning of the analytical run. Instrument blanks were run before and after the calibration curve and every 9 samples.

Quantification of PFAS from the adsorption studies at [PFAS $]_{0}=1 \mu \mathrm{g} \mathrm{L}^{-1}$ in $1 \mathrm{mM}$ phosphate buffer was conducted using large volume injection and high performance liquid chromatography (LC) coupled with a quadrupole-orbitrap mass spectrometer (QExactive, ThermoFisher Scientific). Briefly, the mobile phase consisted of (A) Milli-Q water amended with $20 \mathrm{mM}$ ammonium acetate and (B) HPLC-grade methanol. Samples were injected at $5 \mathrm{~mL}$ volumes onto a Hypersil Gold 
dC18 $12 \mu \mathrm{m} 2.1 \times 20 \mathrm{~mm}$ trap column (ThermoFisher Scientific) and were eluted onto an Atlantis $\mathrm{dC} 185 \mu \mathrm{m} 2.1 \times 150 \mathrm{~mm}$ analytical column (Waters) with a gradient pump delivering $300 \mu \mathrm{L} \mathrm{min}^{-}$ 1 of a mobile phase gradient starting at $40 \%$ B. The column temperature was held constant at $25^{\circ} \mathrm{C}$. The HPLC-MS was operated with electrospray ionization in negative polarity mode. Matrixmatched calibration standards $(n=9)$ were prepared with concentrations ranging between $0 \mathrm{ng}$ $\mathrm{L}^{-1}$ to $1000 \mathrm{ng} \mathrm{L^{-1 }}$ for external calibration. Analytes were quantified from calibration standards based on the PFAS responses by linear least-squares regression. Calibration curves were run at the beginning of the analytical run. Instrument blanks were run before and after the calibration curve and each batch of triplicate samples.

Infrared spectroscopy was performed on a Thermo Nicolet iS10 with a ZnSe crystal ATR attachment.

Elemental analysis was performed by Robertson Microlit Laboratories. Carbon, hydrogen, and nitrogen were quantified by combustion analysis and Fluorine elemental analysis was done by ion-selective electrode methodology.

Zeta potential measurements were performed on a Nano Zetasizer (Malvern Instruments Ltd.) with a He-Ne laser $(633 \mathrm{~nm}$, Max $5 \mathrm{~mW})$.

Solution ${ }^{19} \mathrm{~F}$ NMR was performed on an Agilent DD2 $500 \mathrm{MHz}$ system. (Integrated Molecular Structure Education and Research Center)

Solid state ${ }^{19} \mathrm{~F}$ NMR was performed on a Bruker $600 \mathrm{MHz} 89 \mathrm{~mm}$ system (National High Magnetic Field Laboratory, FL). $600 \mathrm{MHz} 1.3 \mathrm{~mm}$ Fast MAS probe, 1H-X (Bruker H13755) was used. 1D ${ }^{19} \mathrm{~F}$ MAS NMR analysis was performed and the spinning rate was $48 \mathrm{kHz}$, with 1024 scans per sample. Spectra was referenced by external reference at $-61.5 \mathrm{ppm}$.

\section{Synthetic Procedures}

\section{A. Polymer Synthesis}

Synthesis Procedure for DFB-CDP-1: Anhydrous DMSO was dried with activated 4Å molecular sieves before use. An oven-dried $15 \mathrm{~mL}$ heavy-wall pressure vessel equipped with a cylindrical magnetic stir bar was charged with $\beta-C D(0.400 \mathrm{~g}, 0.352 \mathrm{mmol})$, DFB $(0.353 \mathrm{~g}, 1.056 \mathrm{mmol})$, and $\mathrm{K}_{2} \mathrm{CO}_{3}(0.613 \mathrm{~g}, 4.435 \mathrm{mmol})$. The vessel was then bubbled with $\mathrm{N}_{2}$ gas for $5 \mathrm{~min}$. Anhydrous DMSO was added to the vial and $\mathrm{N}_{2}$ gas was purged into the vial for $10 \mathrm{~min}$. The vessel was placed on a hot stirring plate $\left(85^{\circ} \mathrm{C}\right)$ and stirred at $600 \mathrm{rpm}$ for 40 hours. The gel was cooled and then packed into a teabag, and the solid was activated by soxhlet extraction by $\mathrm{H}_{2} \mathrm{O}$ for 30 hours and by methanol for 1 day. Finally, the gel was dried under vacuum at room temperature overnight, 
then dried in vacuum oven at $90{ }^{\circ} \mathrm{C}$ overnight. DFB-CDP-1 $(0.552 \mathrm{~g}, 73.3 \%$ yield) was obtained as a white powder and subsequently characterized. Elemental analysis: $\mathrm{C}, 41.2 ; \mathrm{H}, 3.84 ; \mathrm{F}, 20.14$. IR (ATR): 3404.45 (O-H stretch), 2930.20 (Aliphatic C-H stretch), 1650.63 (Aromatic C=C stretch), 1485.91, 1370.40, 1088.14, 1024.77 (C-O stretch), 979.17, 858.34, $726.10 \mathrm{~cm}^{-1}$. S $\mathrm{BET}$ : No value could be generated because of non-porosity.

Synthesis Procedure for DFB-CDP-2: A $20 \mathrm{~mL}$ scintillation vial equipped with a magnetic stir bar was charged with $\beta-C D(0.400 \mathrm{~g}, 0.352 \mathrm{mmol})$, DFB $(0.353 \mathrm{~g}, 1.056 \mathrm{mmol}), \mathrm{K}_{2} \mathrm{CO}_{3}(0.613 \mathrm{~g}$, $4.435 \mathrm{mmol}$ ) and $9.5 \mathrm{~mL}$ anhydrous DMSO, $0.5 \mathrm{~mL}$ Milli-Q water. The vial was placed on a hot stirring plate $\left(85^{\circ} \mathrm{C}\right)$ and stirred at $600 \mathrm{rpm}$ for 48 hours. The vial was cooled and the crude was filtered and neutralized by $1 \mathrm{M} \mathrm{HCl}$, then the solid was washed by soaking in deionized $\mathrm{H}_{2} \mathrm{O}(2 \mathrm{x}$ $50 \mathrm{~mL})$ for $30 \mathrm{~min}$, THF $(1 \times 50 \mathrm{~mL})$ for $30 \mathrm{~min}$, and $\mathrm{CH}_{2} \mathrm{Cl}_{2}(1 \times 50 \mathrm{~mL})$ for $30 \mathrm{~min}$. Finally, the gel was dried under vacuum at room temperature overnight, then dried in vacuum oven at $90{ }^{\circ} \mathrm{C}$ overnight. DFB-CDP-2 (0.485 g, 64.4\% yield) was obtained as a white powder and subsequently characterized. Elemental analysis: C, 43.8; H, 3.61; F, 20.8. IR (ATR): 3394.65 (O-H stretch), 2929.51 (Aliphatic C-H stretch), 1651.27 (Aromatic C=C stretch), 1485.32, 1372.23, 1088.90, 1023.58 (C-O stretch), 847.55, $725.33 \mathrm{~cm}^{-1}$. S porosity.

Synthesis Procedure for DFB-CDP-3: A $20 \mathrm{~mL}$ scintillation vial equipped with a magnetic stir bar was charged with $\beta-C D(0.400 \mathrm{~g}, 0.352 \mathrm{mmol})$, DFB $(0.353 \mathrm{~g}, 1.056 \mathrm{mmol}), \mathrm{K}_{2} \mathrm{CO}_{3}(0.613 \mathrm{~g}$, $4.435 \mathrm{mmol}$ ) and $9 \mathrm{~mL}$ anhydrous DMSO, $1 \mathrm{~mL}$ Milli-Q water. The vial was placed on a hot stirring plate $\left(85^{\circ} \mathrm{C}\right)$ and stirred at $600 \mathrm{rpm}$ for 48 hours. The vial was cooled and the crude was filtered and neutralized by $1 \mathrm{M} \mathrm{HCl}$, then the solid was washed by soaking in deionized $\mathrm{H}_{2} \mathrm{O}(2 \times 50 \mathrm{~mL})$ for $30 \mathrm{~min}$, THF $(1 \times 50 \mathrm{~mL})$ for $30 \mathrm{~min}$, and $\mathrm{CH}_{2} \mathrm{Cl}_{2}(1 \times 50 \mathrm{~mL})$ for $30 \mathrm{~min}$. Finally, the gel was dried under vacuum at room temperature overnight, then dried in vacuum oven at $90{ }^{\circ} \mathrm{C}$ overnight. DFB-CDP-3 (0.439 g, 58.2\% yield) was obtained as a white powder and subsequently characterized. Elemental analysis: C, 44.8; H, 3.41; F, 21.8. IR (ATR): 3381.53 (O-H stretch), 2928.53 (Aliphatic C-H stretch), 1651.09 (Aromatic C=C stretch), 1484.17, 1370.94, 1086.98, 1019.24 (C-O stretch), 861.05, 724.43, $663.90 \mathrm{~cm}^{-1}$. $\mathrm{S}_{\mathrm{BET}}$ : No value could be generated because of non-porosity.

Synthesis Procedure for EPI-CDP: $\beta-C D(2.996 \mathrm{~g}, 2.64 \mathrm{mmol})$ was dissolved in aqueous $\mathrm{NaOH}$ $\left(1.25 \mathrm{~g}, 31.25 \mathrm{mmol} \mathrm{NaOH}\right.$ in $5.00 \mathrm{~mL}$ Milli-Q water) at $60^{\circ} \mathrm{C}$. Epichlorohydrin $(2.50 \mathrm{~mL}, 32.4$ $\mathrm{mmol}$ ) was added to this solution dropwise while stirring vigorously at $60{ }^{\circ} \mathrm{C}$. The mixture turned into a yellow gel within 1 hour, after which $10 \mathrm{~mL}$ of deionized $\mathrm{H}_{2} \mathrm{O}$ was added, and the mixture 
was filtered on a Büchner funnel. The solid was washed by soaking in deionized $\mathrm{H}_{2} \mathrm{O}(2 \times 100$ $\mathrm{mL})$ for 0.5 hour, THF $(1 \times 100 \mathrm{~mL})$ for $30 \mathrm{~min}$, acetone $(1 \times 100 \mathrm{~mL})$ for $30 \mathrm{~min}$, and $\mathrm{CH}_{2} \mathrm{Cl}_{2}(1 \times$ $100 \mathrm{~mL}$ ) for $15 \mathrm{~min}$. The solid was finally dried under high vacuum at room temperature for 24 hours to give EPI-CDP (3.01 g, $50.2 \%$ yield) as a white powder. Elemental analysis: C, 46.06; $\mathrm{H}$, 6.68. IR (ATR): 3393.44 (O-H stretch), 2879.64 (Aliphatic C-H stretch), 1361.13, 1027.43 (C-O stretch), 855.11, 730.50, $699.80 \mathrm{~cm}^{-1}$. $\mathrm{S}_{\mathrm{BET}}: 3.99 \mathrm{~m}^{2} \mathrm{~g}^{-1}$.

\section{Synthesis Procedure for IEM-CDP:}

Monomer $\beta$-cyclodextrin-isocyanatoethyl methacrylate (IEM-CD): Anhydrous $\beta$-cyclodextrin $(5.83 \mathrm{~g}, 5.14 \mathrm{mmol})$ was weighed and stirred in $41 \mathrm{~mL}$ anhydrous DMF in a $250 \mathrm{~mL}$ round bottom flask at $80{ }^{\circ} \mathrm{C}$ until completely dissolved to give a clear solution. Subsequently, isocyanatoethyl methacrylate (IEM, $2.39 \mathrm{~g}, 15.42 \mathrm{mmol}$ ), dibutyltin dilaurate (DBTDL, $107 \mathrm{mg}$ ), and dibutylhydroxytoluene (BTH, $20 \mathrm{mg}$ ) were added and the reaction mixture was allowed to stir at room temperature for 48 hours. Afterward, the solution was slowly poured into $700 \mathrm{~mL}$ toluene followed by filtration of the resulting precipitates. The filtrates were washed with toluene and dried under vacuum to yield the IEM-CD monomer with near-quantitative yield (>95\%).

Poly ( $\beta$-cyclodextrin-isocyanatoethyl methacrylate) (IEM-CDP): The IEM-CD monomer (1.02 g) and $10 \mathrm{wt} \%$ AIBN initiator (102 $\mathrm{mg}, 0.62 \mathrm{mmol}$ ) were dissolved in $3 \mathrm{~mL} \mathrm{DMF}$ and $1 \mathrm{~mL}$ THF in a $20 \mathrm{~mL}$ vial equipped with a stirring bar. The reaction vessel was degassed by three freezepump-thaw cycles and then placed in a preheated oil bath at $80{ }^{\circ} \mathrm{C}$ and allowed to vigorously stir overnight. After 14 hours, the solids were washed with THF (2 x $5 \mathrm{~mL})$, EtOAc $(2 \times 5 \mathrm{~mL})$, DMF $(2 \times 5 \mathrm{~mL})$, and $\mathrm{H}_{2} \mathrm{O}(3 \times 5 \mathrm{~mL})$ via centrifugation. Finally, the isolated product was lyophilized for 48 hours to yield IEM-CDP polymer as a white powder with near-quantitative yield (>90\%). Elemental analysis: C, 44.65; H, 6.24; N, 2.91. IR (ATR): 3373.37 (O-H stretch), 2931.84 (Aliphatic C-H stretch), 1708.12 (C=O stretch), 1530.32, 1255.61, 1153.74, 1028.40 (C-O stretch), $844.94,759.29 \mathrm{~cm}^{-1}$. $\mathrm{S}_{\mathrm{BET}}: 3.36 \mathrm{~m}^{2} \mathrm{~g}^{-1}$.

\section{B. Model Reactions}

Due to the addition of water to DMSO in model reaction 2 and 3 (Scheme 2), the solubility of nonpolar 1a in the solution decreased and part of 1a precipitated after the reactions were cooled to room temperature. We analyzed the products in aqueous phase and solid phase separately to keep track of the conversion of DFB.

Substitution of DFB with $n$-BuOH: DFB $(0.353 \mathrm{~g}, 1.056 \mathrm{mmol})$ and $\mathrm{K}_{2} \mathrm{CO}_{3}(0.613 \mathrm{~g}, 4.435 \mathrm{mmol})$ were added to a flame-dried, $20 \mathrm{~mL}$ scintillation vial equipped with a magnetic stir bar. To Model 
reaction 1) Anhydrous DMSO (10 mL); 2) Anhydrous DMSO (9.5 mL) and $\mathrm{H}_{2} \mathrm{O}(0.5 \mathrm{~mL}) ; 3$ ) Anhydrous DMSO $(9 \mathrm{~mL})$ and $\mathrm{H}_{2} \mathrm{O}(1 \mathrm{~mL})$ were then added and the vial was purged with $\mathrm{N}_{2}$ for $10 \mathrm{~min} . n$ - $\mathrm{BuOH}(0.226 \mathrm{~mL}, 2.464 \mathrm{mmol})$ was added and the vial was stirred at $85^{\circ} \mathrm{C} .40-48$ hours later (40 hours for model reaction 1, 48 hours for model reaction 2 and 3), the vial was cooled down to room temperature and sonicated to get a good suspension, aliquots $(1 \mathrm{~mL})$ were taken and centrifuged, the supernatant and the sediment were separated. The supernatant was marked as 1/2/3-Liquid phase, it was then mixed with DMSO-d $\mathrm{d}_{6}$ and $5 \mathrm{mg}$ a, $\alpha, \alpha-$ trifluorotoluene. The sediment was mixed with $1 \mathrm{~mL}$ DMSO- $\mathrm{d}_{6}$ and sonicated for 5 minutes to get products residuals in the solid phase dissolved into the liquid phase, the suspension was centrifuged and the supernatant was labeled as 1/2/3-Solid phase, which was mixed with $5 \mathrm{mg}$ a, $\alpha$, $\alpha$-trifluorotoluene.

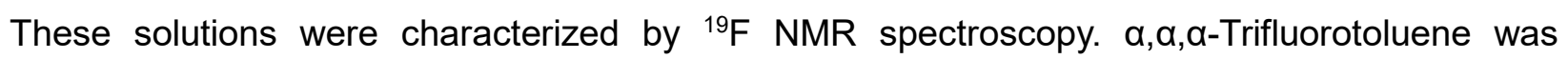
employed as an internal standard to quantify fluorinated species using ${ }^{19} \mathrm{~F} N M R$ spectroscopy. ${ }^{19} \mathrm{~F}$ NMR Chemical shift (ppm): 1a: $\delta=-143.01(4 F),-159.09(4 F) ; 1 b: \delta=-142.13(2 F),-151.20(2 F)$, $158.02(1 F),-165.36(2 F),-171.37(2 F) ; 2 b: \delta=-143.60(2 F),-151.30(2 F),-160.32(2 F),-171.40$ $(2 \mathrm{~F}) ; 3 \mathrm{~b}: \delta=-151.10(4 \mathrm{~F}),-171.97(4 \mathrm{~F})$. Splitting patterns and detailed assignment of fluorine peaks of $\mathbf{1 a}, \mathbf{1 b}, \mathbf{2} \mathbf{b}$ could be found in a previous report. ${ }^{1}$ Detailed ${ }^{19} \mathrm{~F}-\mathrm{NMR}$ spectra of $\mathbf{3} \mathbf{b}$ is shown in Figure S2. Percentages of these species in the reaction crudes were listed in Table S1.

Table S1: Percentages of 1a, 1b, 2b, 3b in model reaction 1-3.

\begin{tabular}{ccccccc}
\hline & $\mathbf{1}$ & \multicolumn{2}{c}{$\mathbf{2}$} & $\mathbf{3}$ & \\
\cline { 2 - 7 } Sample & $\begin{array}{c}\text { Liquid } \\
\text { Phase }\end{array}$ & $\begin{array}{c}\text { Solid } \\
\text { Phase }\end{array}$ & $\begin{array}{c}\text { Liquid } \\
\text { Phase }\end{array}$ & $\begin{array}{c}\text { Solid } \\
\text { Phase }\end{array}$ & $\begin{array}{c}\text { Liquid } \\
\text { Phase }\end{array}$ & $\begin{array}{c}\text { Solid } \\
\text { Phase }\end{array}$ \\
\hline 1a & 79.6 & 3.88 & 35.6 & 25.1 & 12.4 & 35.9 \\
\hline 1b & 4.49 & 0.444 & 10.8 & 2.44 & 10.2 & 0 \\
\hline 2b & 7.33 & 0.375 & 19.6 & 1.75 & 35.8 & 0 \\
\hline 3b & 0 & 0 & 2.5 & 0 & 6.38 & 0 \\
\hline
\end{tabular}

Acidification of Model Reaction 3-Liquid phase: $100 \mu \mathrm{L} 1 \mathrm{M} \mathrm{HCl}$ was added to $0.5 \mathrm{~mL}$ of model reaction 3-Liquid phase and $\mathrm{pH}$ was adjusted to $1.0 .2 \mathrm{~mL} \mathrm{DMSO}-\mathrm{d}_{6}$ was added to the acidified model reaction 3-Liquid phase. The acidified crude was centrifuged and supernatant was mixed with $\alpha, \alpha, \alpha$-trifluorotoluene. The solution was then characterized by ${ }^{19} \mathrm{~F}$ NMR spectroscopy. The chemical shift changes of $\mathbf{2} \mathbf{b}$ before and after the acidification are shown in Figure S1. ${ }^{19} \mathrm{~F}$ NMR Chemical shift (ppm): 2b: $\delta=-143.6(2 F),-151.3(2 F),-160.3(2 F),-171.4(2 F) ; 2 b ': ~ \delta=-143.2$ (2F), -144.4 (2F), -159.3 (2F), -163.3 (2F). 


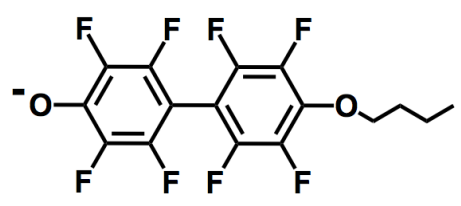

123

$2 b$

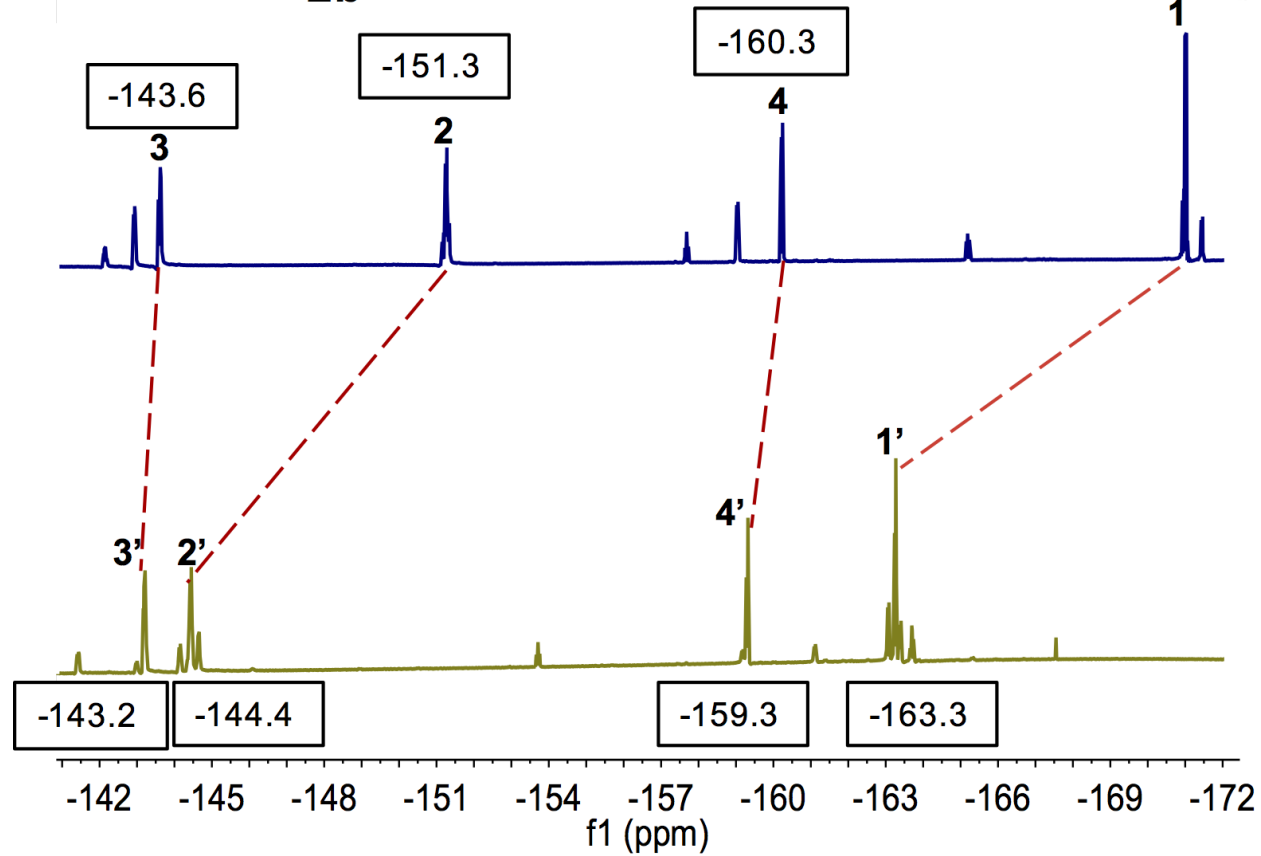<smiles>CCCCOc1c(F)c(F)c(-c2c(F)c(F)c(O)c(F)c2F)c(F)c1F</smiles>

1' 2' 3' 4'

2b'

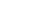

$-171.4$

Figure S1: ${ }^{19} \mathrm{~F}$ NMR spectra (500 MHz, DMSO- $\mathrm{d}_{6}$ ) with peaks labeled for $\mathbf{2} \mathbf{b}$ and $\mathbf{2} \mathbf{b}$ ' (from model reaction 3-Liquid phase).

Formation and Identification of 3b: DFB (0.353 g, $1.056 \mathrm{mmol})$ and $\mathrm{K}_{2} \mathrm{CO}_{3}(0.613 \mathrm{~g}, 4.435$ $\mathrm{mmol}$ ) were added to a flame-dried, $20 \mathrm{~mL}$ scintillation vial equipped with a magnetic stir bar. To model reaction 4) Anhydrous DMSO (5 mL) and $\mathrm{H}_{2} \mathrm{O}(5 \mathrm{~mL})$ were then added and the vial was purged with $\mathrm{N}_{2}$ for $10 \mathrm{~min}$. $n-\mathrm{BuOH}(0.226 \mathrm{~mL}, 2.464 \mathrm{mmol})$ was added and the vial was stirred at $85^{\circ} \mathrm{C} .40$ hours later, the vial was cooled down and sonicated to get nice suspension, aliquots $(1 \mathrm{~mL})$ were taken and centrifuged. $0.5 \mathrm{~mL}$ of the supernatant was mixed with DMSO- $\mathrm{d}_{6}$ and $\alpha, \alpha, \alpha-$ trifluorotoluene, marked as 4-Liquid phase. The solution was characterized by ${ }^{19} \mathrm{~F}$ NMR spectroscopy and one of the major products is $\mathbf{3 b}$. The fluorine peaks of $\mathbf{3 b}$ are assigned in Figure S2. ${ }^{19} \mathrm{~F}$ NMR Chemical shift (ppm): 3b: $\delta=-150.79(4 \mathrm{~F}),-170.28(4 \mathrm{~F})$ (The chemical shifts of fluorine peaks of $\mathbf{3 b}$ in this reaction were slightly different from those of $\mathbf{3 b}$ in model reaction 1-3 due to solvent effects). 


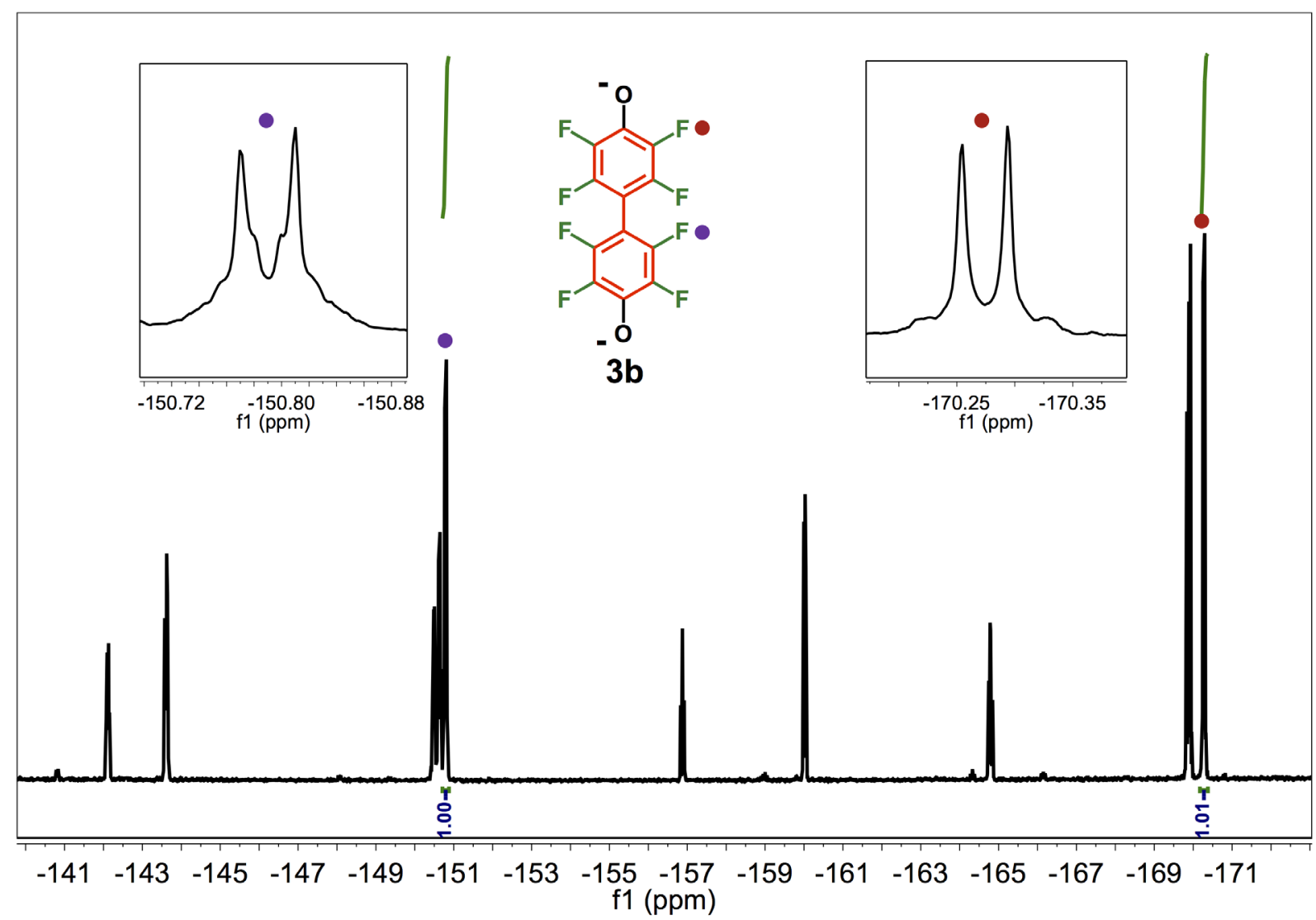

Figure S2: ${ }^{19} \mathrm{~F}$ NMR spectra $\left(500 \mathrm{MHz}\right.$, DMSO- $\mathrm{d}_{6}$ ) with peaks labeled for $\mathbf{3 b}$ (from model reaction 4-Liquid phase).

\section{Materials Characterization}

A. Solid state ${ }^{19}$ F NMR of DFB-CDP. 


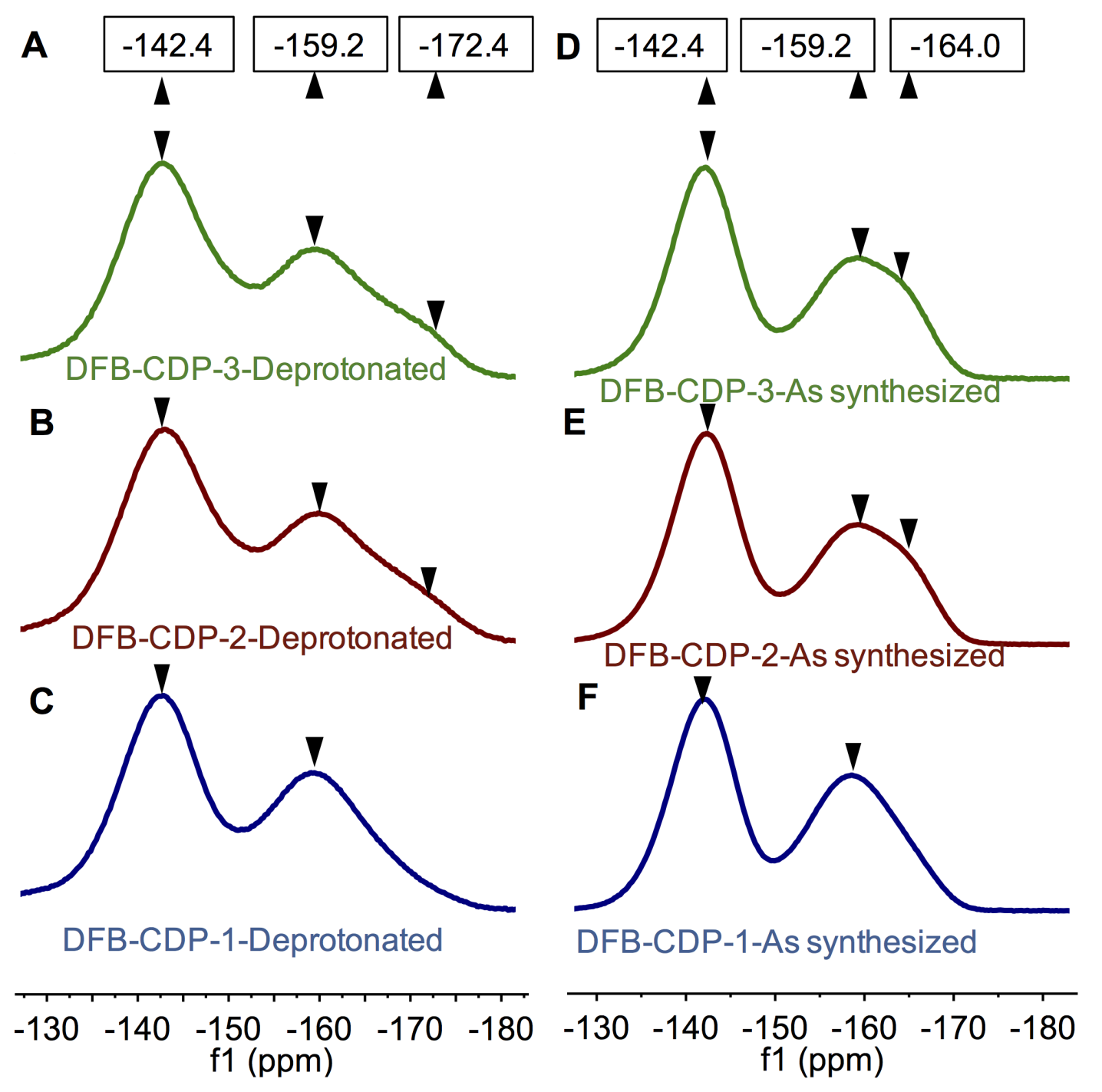

Figure S3: ${ }^{19} \mathrm{~F}$ MAS NMR of deprotonated and as-synthesized DFB-CDPs.

\section{B. FT-IR of $\beta$-CD Polymers}




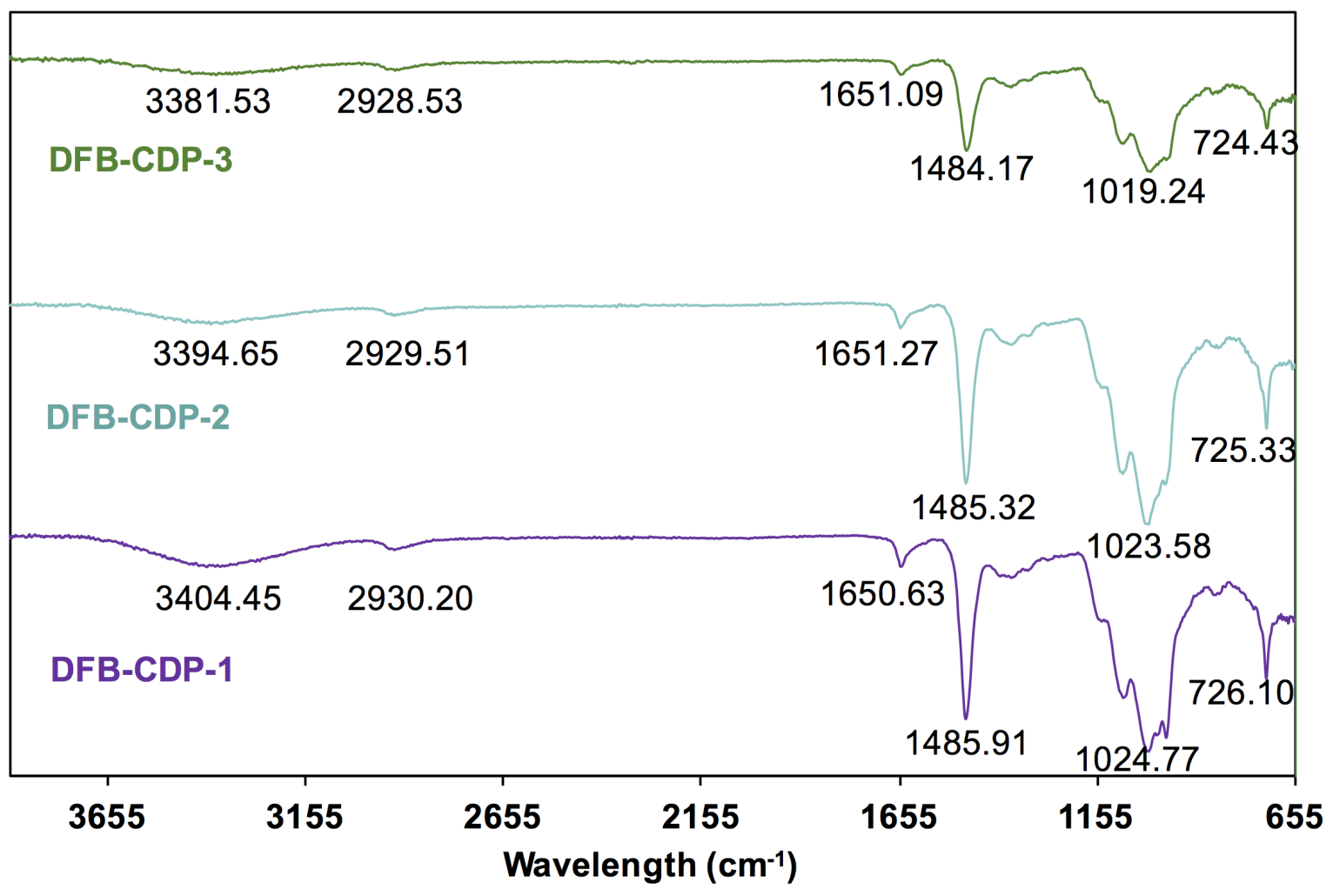

Figure S4: FT-IR (ATR) of as-synthesized DFB-CDPs. (Green: DFB-CDP-3; Blue: DFB-CDP-2; Purple: DFB-CDP-1.) 


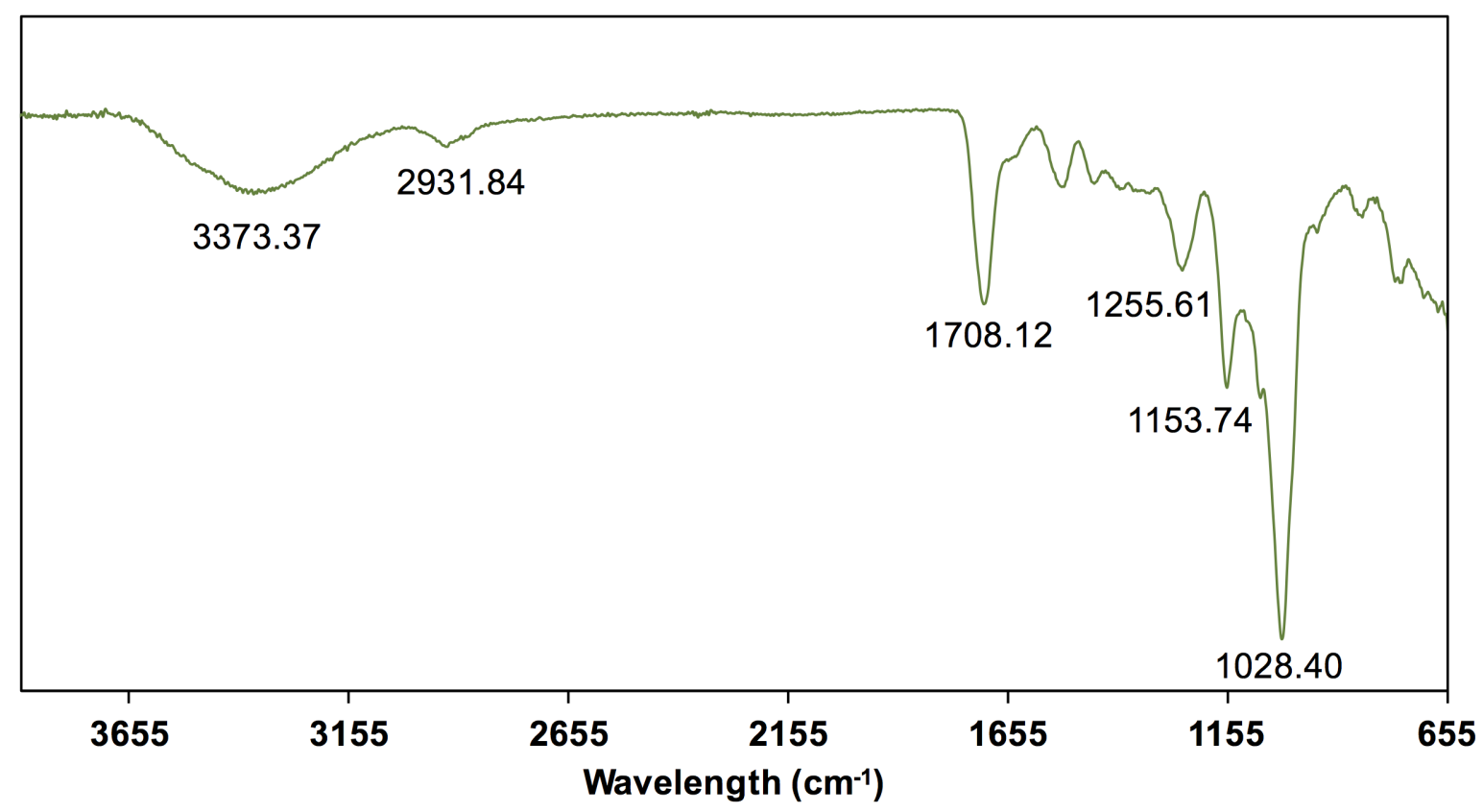

Figure S5: FT-IR (ATR) of as-synthesized IEM-CDP.

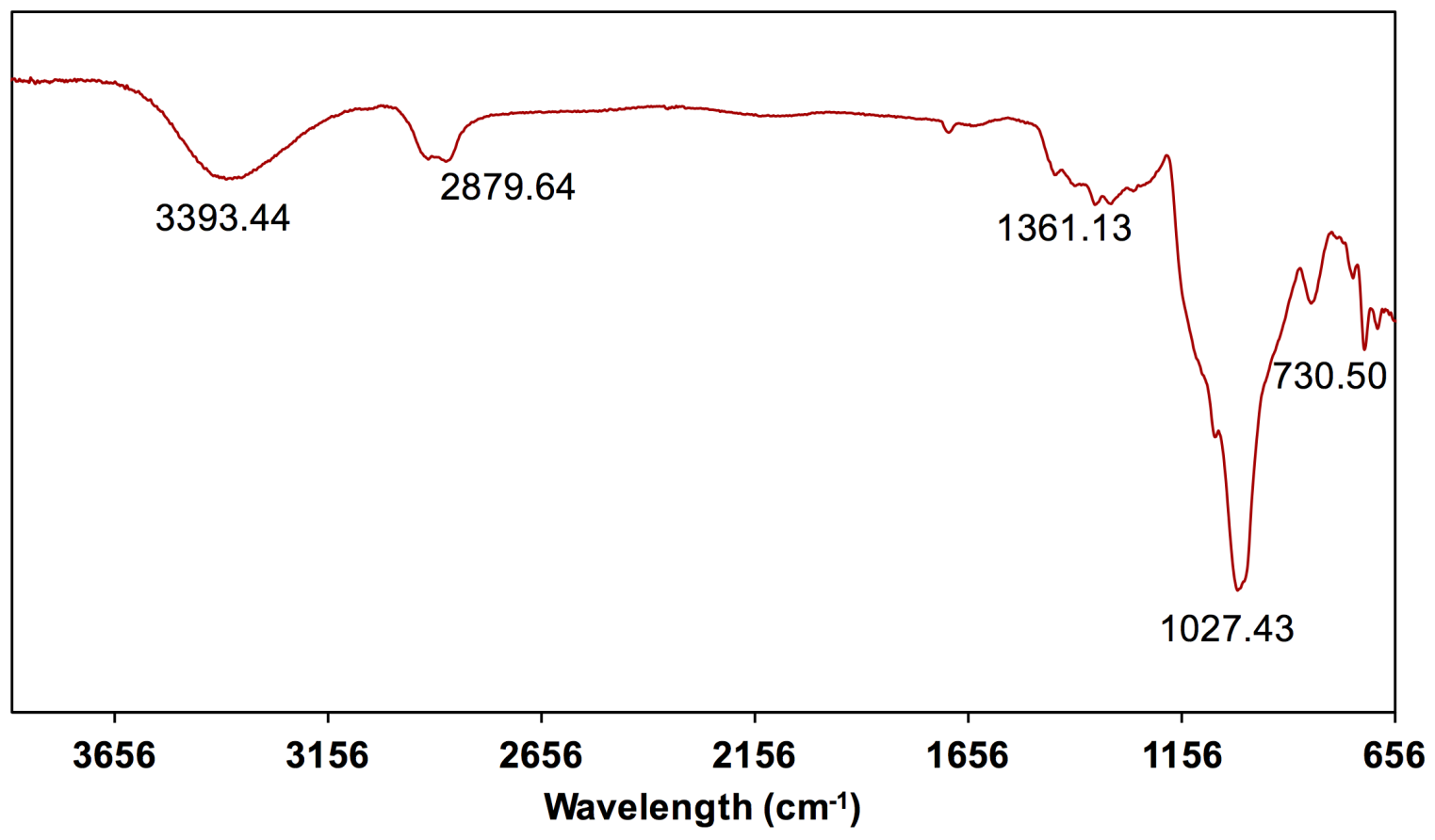

Figure S6: FT-IR (ATR) of as-synthesized EPI-CDP.

C. Zeta Potential Studies of $\beta-C D$ Crosslinked Polymers 
The zeta potentials of $\beta-C D$ polymers at $\mathrm{pH} 5.5$ and 7.5 were determined with $100 \mathrm{mg} / \mathrm{L}$ polymer in $9 \mathrm{mM}$ phosphate buffer at $25^{\circ} \mathrm{C}$, and the $\mathrm{pH}$ at 5.5 was adjusted by concentrated hydrochloric acid. Zeta potential measurements were performed on a Nano Zetasizer (Malvern Instruments Ltd.) with a He-Ne laser (633 nm, Max $5 \mathrm{~mW}$ ). Five $\beta-C D$ polymers were tested, including EPICDP, IEM-CDP and DFB-CDPs.

$10 \mathrm{mg}$ of each polymer was added to a $20 \mathrm{~mL}$ scintillation vial with $10 \mathrm{~mL}$ Milli-Q water to yield a $1 \mathrm{~g} / \mathrm{L}$ suspension and then sonicated for 1 minute to disperse small aggregates and then stirred on a stirrer for 24 hours at $500 \mathrm{rpm}$. $1 \mathrm{~mL}$ of the $1 \mathrm{~g} / \mathrm{L}$ suspension was added to a $20 \mathrm{~mL}$ polypropylene vial with $9 \mathrm{~mL} 10 \mathrm{mM}$ phosphate buffer ( $\mathrm{pH}$ at 5.5 or 7.5), and then stirred on a stirrer for 4 hours at $500 \mathrm{rpm}$. The $\mathrm{pH}$ of the $100 \mathrm{mg} / \mathrm{L}$ polymer suspension in $9 \mathrm{mM}$ phosphate buffer was measured by $\mathrm{pH}$ meter after 4-hour stir. Before each measurement of the zeta potential, the polymer suspension was shaken and $1 \mathrm{~mL}$ aliquot was transferred to folded capillary cell. Each sample was measured in triplicate.

Table S2: Zeta potential values of five $\beta-\mathrm{CD}$ polymers at $\mathrm{pH} 5.5$ and 7.5.

\begin{tabular}{ccc}
\hline Sample & $\begin{array}{c}\text { Zeta Potential } \\
\text { at pH 7.5 }(\mathbf{m V})\end{array}$ & $\begin{array}{c}\text { Zeta Potential at } \\
\mathbf{p H} \mathbf{5 . 5}(\mathbf{m V})\end{array}$ \\
\hline EPI-CDP & $-1.29 \pm 0.55$ & $-0.87 \pm 0.23$ \\
\hline IEM-CDP & $-9.16 \pm 0.43$ & $-4.46 \pm 0.23$ \\
\hline DFB-CDP-1 & $-14.5 \pm 0.31$ & $-7.0 \pm 0.61$ \\
\hline DFB-CDP-2 & $-20.3 \pm 0.75$ & $-11.2 \pm 0.61$ \\
\hline DFB-CDP-3 & $-22.9 \pm 0.83$ & $-11.6 \pm 0.35$ \\
\hline
\end{tabular}

\section{Phenolation Studies of $\beta-C D$ Crosslinked Polymers}

The concentrations of phenolated crosslinker in the DFB $\beta-C D$ polymers were determined by acidification by $\mathrm{HCl}$, deprotonating the phenolated crosslinker with concentrated $\mathrm{Li}_{2} \mathrm{CO}_{3}$, then digesting the polymers and analyzing the concentrations of $\mathrm{Li}^{+}$by ICP-OES. Since one phenolated crosslinker binds with one $\mathrm{Li}^{+}$, the concentration of the phenolated crosslinker could be calculated based on $\left[\mathrm{Li}^{+}\right]$. $\mathrm{Li}^{+}$binding by EPI-CDP and IEM-CDP were also quantified using the same procedure.

$150 \mathrm{mg}$ of each polymer was suspended in $15 \mathrm{~mL} 1 \mathrm{~mol} \mathrm{~L}-1 \mathrm{HCl}$ for 30 minutes, filtered and washed copiously with $30 \mathrm{~mL}$ Milli-Q water. These samples were dried in a vacuum oven at 90 ${ }^{\circ} \mathrm{C}$ for 12 hours. Dried samples (25 mg, triplicate of each polymer) were then mixed in a concentrated $\mathrm{Li}_{2} \mathrm{CO}_{3}\left(12 \mathrm{~g} \mathrm{~L}^{-1}, 2.5 \mathrm{~mL}\right)$ solution for 30 minutes. These samples were then filtered and washed with Milli-Q water $(5 \mathrm{~mL})$ on the filter cake to wash out excess $\mathrm{Li}_{2} \mathrm{CO}_{3}$. The samples 
were dried in a vacuum oven at $90{ }^{\circ} \mathrm{C}$ for 12 hours. Transfer the samples to the microwave tubes and measure the mass of the solid transferred. The samples were then digested in $\mathrm{HNO}_{3}(70 \%$, $8 \mathrm{~mL})$ and $\mathrm{H}_{2} \mathrm{O}_{2}(30 \%, 2 \mathrm{~mL})$ in a microwave at $180{ }^{\circ} \mathrm{C}(10 \mathrm{~min}$ ramp, $30 \mathrm{~min}$ hold, $30 \mathrm{~min}$ exhaustion).

The clear solutions $(1 \mathrm{~mL})$ of digested samples were diluted with $9 \mathrm{~mL}$ Milli-Q water and injected into ICP-OES for $\mathrm{Li}^{+}$quantification. After second oven drying, every transfer of the mass of the solid, solutions and dilutions were taken for accuracy. Six calibration standards of $\mathrm{Li}^{+}$with same matrix as diluted digested samples were prepared. The concentrations of standards from 1 to 6 are: $10,5,2.5,1.25,0.625,0.3125 \mathrm{ppm}$. The mass of the standards was measured after the addition of each reagent so that the accurate concentrations of standards could be calculated based on mass.

Table S3: Volumes of reagents in serial dilution of $\mathrm{Li}^{+}$standards 1-6.

\begin{tabular}{|c|c|c|c|c|}
\hline STD & $\mathrm{V}_{\mathrm{H} 2 \mathrm{O}}(\mathrm{mL})$ & $\mathrm{V}_{\mathrm{HNO}_{3}}(\mathrm{~mL})$ & $\mathrm{V}_{\mathrm{H} 2 \mathrm{O} 2}(\mathrm{~mL})$ & $\begin{array}{c}\text { Additional } \\
\mathrm{V}_{1000 \mathrm{ppm} \mathrm{Li}}{ }^{+}(\mathrm{mL}) \\
\end{array}$ \\
\hline 1 & 45 & 4 & 1 & $\begin{array}{c}0.5 \mathrm{~mL} \text { of the } \mathrm{HNO}_{3}+\mathrm{H}_{2} \mathrm{O}_{2} \\
\text { solution was taken out, and } 0.5 \\
\mathrm{~mL} \text { of } 1000 \mathrm{ppm} \mathrm{Li} \text { was added }\end{array}$ \\
\hline 2 & 22.5 & 2 & 0.5 & Add $25 \mathrm{~mL}$ of STD 1 \\
\hline 3 & 22.5 & 2 & 0.5 & Add $25 \mathrm{~mL}$ of STD 2 \\
\hline 4 & 22.5 & 2 & 0.5 & Add $25 \mathrm{~mL}$ of STD 3 \\
\hline 5 & 22.5 & 2 & 0.5 & Add $25 \mathrm{~mL}$ of STD 4 \\
\hline 6 & 22.5 & 2 & 0.5 & Add $25 \mathrm{~mL}$ of STD 5 \\
\hline
\end{tabular}

\section{Batch Adsorption Studies}

\section{A. PFOA adsorption studies by DFB-CDPs in Milli-Q water}

The batch adsorption experiments at $1 \mu \mathrm{g} \mathrm{L} \mathrm{L}^{-1}$ PFOA by DFB $\beta$-CD polymers were performed in $20 \mathrm{~mL}$ Kimble Chase ${ }^{\mathrm{TM}}$ polypropylene scintillation vial at $23-24{ }^{\circ} \mathrm{C}$ on a stirring plate with the stirring rate at 500 revolutions per minute (rpm). The adsorbent dose was $10 \mathrm{mg} \mathrm{L}^{-1}$ and PFOA stock solution was spiked to generate an initial concentration of $1 \mu \mathrm{g} \mathrm{L}^{-1}$. 
Prior to PFOA adsorption experiments, vacuum-dried adsorbents were rehydrated. $10 \mathrm{mg}$ of sieved adsorbent (DFB-CDPs, $20 \mu \mathrm{m}<$ particle size $<45 \mu \mathrm{m}$ ) was added to a $20 \mathrm{~mL}$ scintillation vial with $10 \mathrm{~mL}$ Milli-Q water to yield a $1 \mathrm{~g} \mathrm{~L}^{-1}$ suspension. The suspension was sonicated for 1 minute to disperse small aggregates and then stirred on a stirrer for 1 hour at $500 \mathrm{rpm}$. After 1 hour stir, $2 \mathrm{~mL} 1 \mathrm{~g} \mathrm{~L}^{-1}$ suspension was added into a $20 \mathrm{~mL}$ scintillation vial with $18 \mathrm{~mL}$ Milli-Q water to yield a $100 \mathrm{mg} \mathrm{L}^{-1}$ suspension and then stirred on a multi-position stirrer for 1 hour at $500 \mathrm{rpm}$. Following this procedure, $2 \mathrm{~mL} 100 \mathrm{mg} \mathrm{L}^{-1}$ suspension and PFOA solution $\left(1 \mathrm{~mL}, 20 \mu \mathrm{g} \mathrm{L}^{-1}\right)$ were added into a $20 \mathrm{~mL}$ polypropylene vial with $17 \mathrm{~mL}$ Milli-Q water to yield a $10 \mathrm{mg} \mathrm{L}^{-1}$ polymer suspension with $[P F O A]_{0}=1 \mathrm{ug} \mathrm{L}^{-1}$ and then stirred on a multi-position stirrer at $500 \mathrm{rpm}$. Samples were collected in $1 \mathrm{~mL}$ volumes at predetermined sampling times $(0.5,1,2,4,6,20,25.5 \mathrm{~h})$ and filtered with $0.22 \mu \mathrm{m}$ cellulose acetate syringe filters. Control experiments to account for PFOA losses were performed in the same condition at 20 and $25.5 \mathrm{~h}$ with no addition of adsorbent. All batch kinetics experiments (including controls) were performed in triplicate. Samples were collected in $1 \mathrm{~mL}$ volumes and analyzed by HPLC-MS.

The efficiency of pollutant removal by the sorbent was determined by Eq. S1:

\section{Equation S1:}

MP Removal $=\frac{C_{0}-C_{t}}{C_{0}} * 100$

where $C_{0}\left(\mu \mathrm{L} \mathrm{L}^{-1}\right)$ and $\mathrm{C}_{\mathrm{t}}\left(\mu \mathrm{g} \mathrm{L}^{-1}\right)$ are the initial and residual concentration of pollutant in the stock solution and filtrate, respectively.

The amount of pollutant bound to the sorbent was determined by Eq. S2:

\section{Equation S2:}

$q_{t}=\frac{C_{0}-C_{t}}{C_{A}}$

where $q_{t}\left(\mathrm{mg} \mathrm{g}^{-1}\right)$ is the amount of a micropollutant adsorbed on the solid phase at any time $t(\mathrm{~h})$; $C_{0}\left(\mu \mathrm{g} \mathrm{L}^{-1}\right)$ is the average concentration of a MP in the samples of the control experiments; $C_{t}(\mu \mathrm{g}$ $\left.\mathrm{L}^{-1}\right)$ is the concentration of a MP in the liquid phase at any sample time $t(\mathrm{~h})$; and $C_{A}\left(\mathrm{mg} \mathrm{L}^{-1}\right)$ is the concentration of adsorbent. The batch kinetics of each adsorbent can then be described with Ho and McKay's pseudo-second-order adsorption model ${ }^{2}$ in a linearized form as Eq. S3:

\section{Equation S3:}


$\frac{t}{q_{t}}=\frac{t}{q_{e}}+\frac{1}{k_{o b s} q_{e}^{2}}$

where $q_{e}\left(\mathrm{mg} \mathrm{g}^{-1}\right)$ is the amount of a MP adsorbed on the solid phase at equilibrium; and $k_{o b s}(\mathrm{~g}$ $\mathrm{mg}^{-1} \mathrm{~h}^{-1}$ ) is the rate constant of adsorption, which was calculated from 0 to $25.5 \mathrm{~h}$. In Figure S7, the slope of each plot corresponds to $1 / q_{e}$, while the intercept corresponds to $1 /\left(k_{o b s} q_{e}{ }^{2}\right)$.
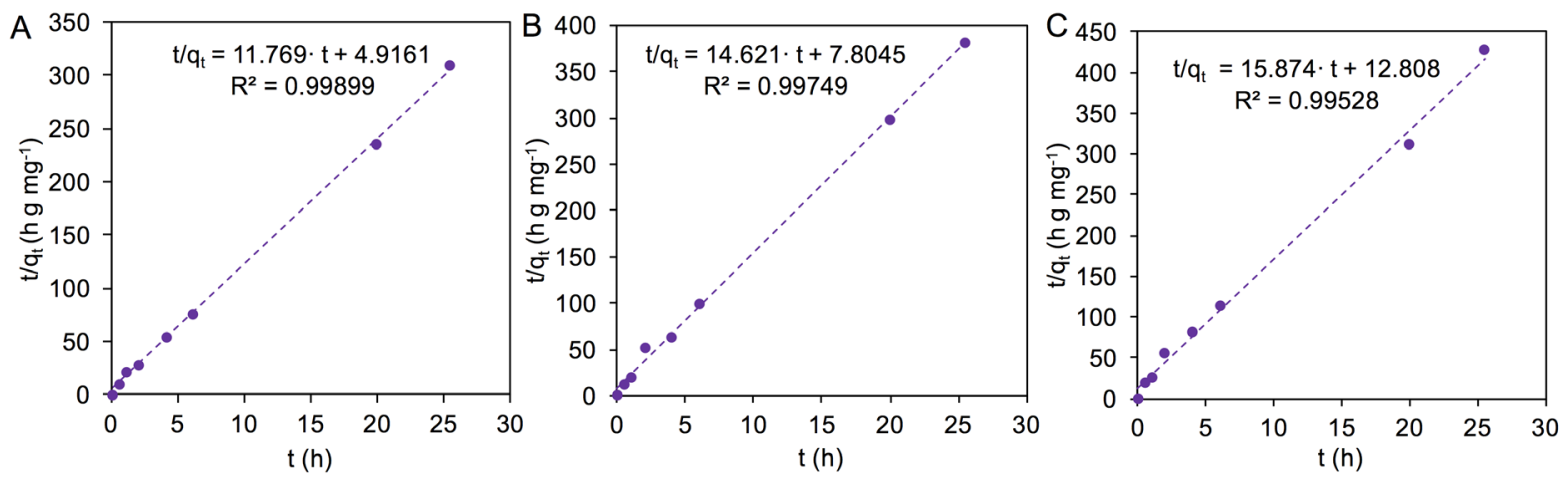

Figure S7. $t / q_{t}$ as a function of time according to pseudo-second order model given in Equation S3: A) DFB-CDP-1; B) DFB-CDP-2; 3) DFB-CDP-3.

\section{B. Ten PFAS Adsorption Study by Five $\beta-C D$ Polymers}

The batch experiments at $1 \mu \mathrm{g} \mathrm{L}^{-1}$ of PFASs were performed in $125 \mathrm{~mL}$ polypropylene flasks with magnetic stir bars. The experiments were conducted at $23{ }^{\circ} \mathrm{C}$ on a stirring plate with the stirring rate at 500 revolutions per minute (rpm). The adsorbent dose was $10 \mathrm{mg} \mathrm{L}^{-1}$ and the PFAS mixture solution was spiked to generate an initial concentration of each PFAS at $1 \mu \mathrm{g} \mathrm{L}^{-1}$. The matrix was $100 \mathrm{~mL}$ of $1 \mathrm{mM}$ phosphate buffer at either $\mathrm{pH} 7.5$ or $\mathrm{pH} 5.5$. Prior to experiments, vacuum-dried adsorbents were rehydrated as previously described. Samples were collected in 8 $\mathrm{mL}$ volumes at 9 hours and filtered with a $0.45 \mu \mathrm{m}$ cellulose acetate filter (Restek), spiked with isotope labelled internal standards $\left({ }^{13} \mathrm{C}_{8}\right.$-PFOA and ${ }^{13} \mathrm{C}_{8}$-PFOS), and measured by means of LCMS as previously described. Separate matrix-matched calibration curves were prepared at each $\mathrm{pH}$. Control experiments to account for PFAS losses were performed at the same condition except for the addition of adsorbents. All batch experiments were performed with triplicates. 


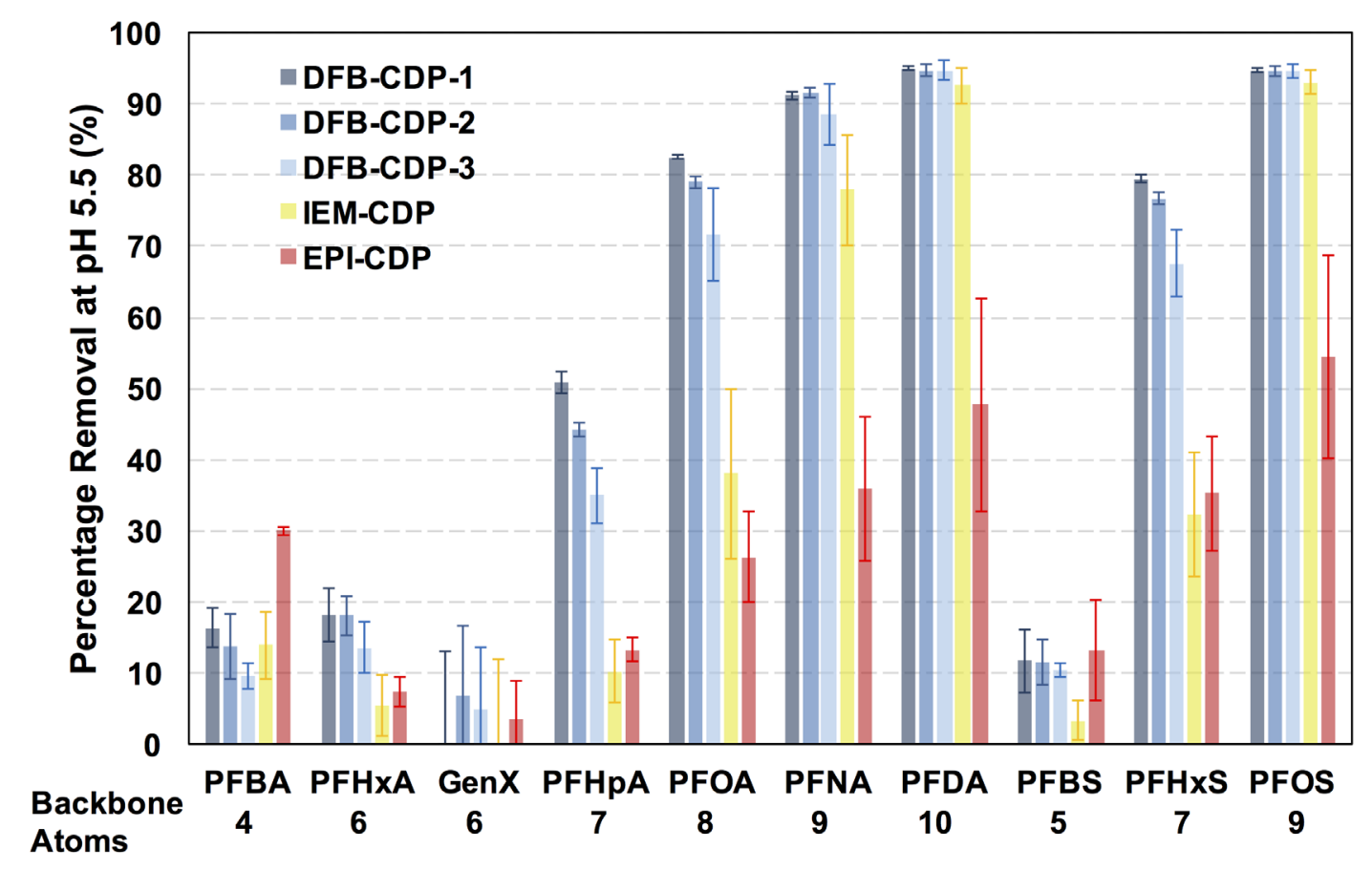

Figure S8. Equilibrium adsorption of 10 PFAS by five $\beta$-CD-based polymers in $1 \mathrm{mM} \mathrm{pH} 5.5$ phosphate buffer ([PFAS $]_{0}=1 \mu \mathrm{g} \mathrm{L}^{-1}$; [Adsorbent] $\left.=10 \mathrm{mg} \mathrm{L}^{-1}\right)$. Error bars: standard deviation of 3 experiments. Bottom row: Backbone atom numbers of each PFAS, including polar head groups.

\section{References}

(1) Xiao, L.; Ling, Y.; Alsbaiee, A.; Li, C.; Helbling, D. E.; Dichtel, W. R. $\beta$-Cyclodextrin Polymer Network Sequesters Perfluorooctanoic Acid at Environmentally Relevant Concentrations. J. Am. Chem. Soc. 2017, 139 (23), 7689-7692.

(2) Ho, Y. S.; McKay, G. Pseudo-second order model for sorption processes. Process Biochem. 1999, 34, 451-465. 